Polymer Journal, Vol. 4, No. 2, pp 213-214 (1973)

SHORT COMMUNICATION

\title{
Spherulites of Poly(2,6-dimethyl-1,4-phenylene oxide)
}

\author{
Shozo Horikiri and Keiko Kodera \\ Central Research Laboratory, Sumitomo Chemical Co., Ltd. \\ Takatsuki, Osaka, Japan. \\ (Received June 14, 1972) \\ KEY WORDS
Tetralin / \\ Poly(phenylene oxide) / Spherulites / $\alpha$-Pinene /
}

Recently, spherulites of poly(2,6-dimethyl-1,4phenylene oxide) have been found to be formed in the film when this film was exposed to $\alpha$-pinene or tetralin vapor.

After drying, these spherulites lose their briefringence, and the crystalline structure of the polymer also collapses. ${ }^{1}$ These facts indicate the important role of the solvent in the crystallization of this polymer, which suggests study of the spherulites formed by solvent vapor exposure on the polymer film would be worthwhile.

In this report, the morphologies of the spherulites formed at several temperatures by exposure of $\alpha$-pinene or tetralin vapor on the polymer films are described. The details of their growing processes will be reported elsewhere in the near future.

The polymer films were prepared by solution casting on a clean microscope slide glass using a $0.5-\%$ chloroform solution. The thickness of the films was about $10 \mu$. These films were further dried under vacuum at $140^{\circ} \mathrm{C}$ for $24 \mathrm{hr}$. Infrared spectroscopy shows no trace of solvent in the films and the thermogram obtained by a differential scanning calorimeter shows the films to be amorphous.

The intrinsic viscosity of the polymer in its chloroform solution at $25^{\circ} \mathrm{C}$ was $52 \mathrm{ml} / \mathrm{g}$.

The films were exposed to $\alpha$-pinene vapor equilibrated with the solvent of which the temperature was $15^{\circ} \mathrm{C}$ higher than that of the films.

Figure 1 shows the spherulites formed at $35^{\circ} \mathrm{C}$. They have a fibrillar appearance and a straight Maltese extinction cross, and are positively birefringent. The spherulites of this type seem to have rather fast growth rates in the early stages of growth, because the spherulites are observed even after $30 \mathrm{~min}$ vapor exposure and further exposure causes little increase in their size.

At $40^{\circ} \mathrm{C}$, banded spherulites are also found in addition to the fibrillar spherulites. The banded spherulites formed at higher temperature than $40^{\circ} \mathrm{C}$ are all negatively birefringent.

Above $40^{\circ} \mathrm{C}$, the fibrillar spherulites are no longer found and only the banded spherulites are

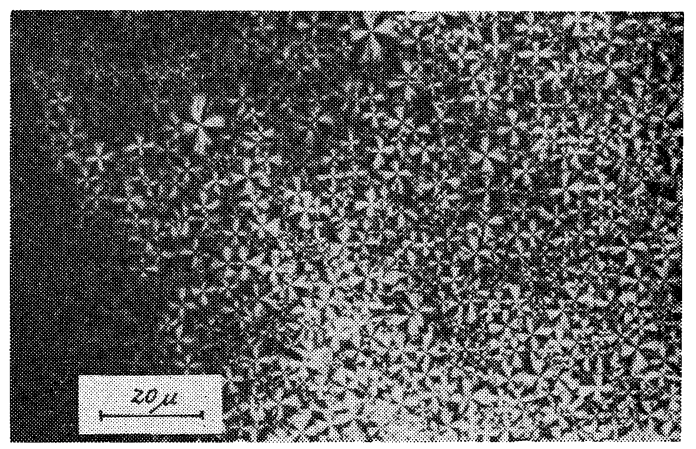

Figure 1. Fibrillar spherulites of poly(2,6-dimethyl1,4-phenylene oxide) formed at $35^{\circ} \mathrm{C}$ by 5 -hr $\alpha$ pinene vapor exposure.

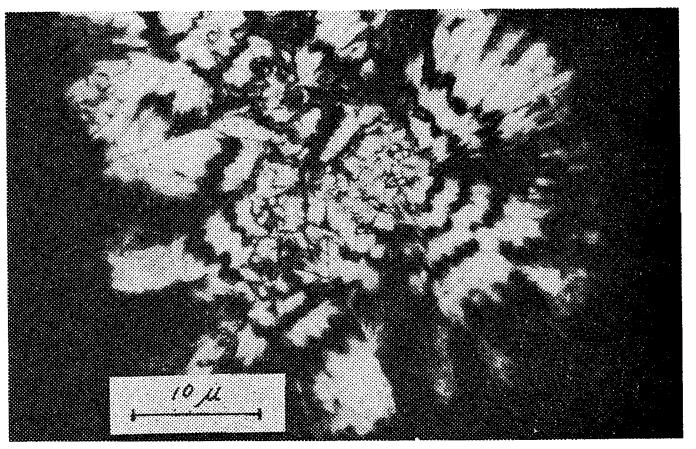

Figure 2. Banded spherulites and their fibrillar overgrowth formed at $50^{\circ} \mathrm{C}$ by $17-\mathrm{hr} \alpha$-pinene vapor exposure. 


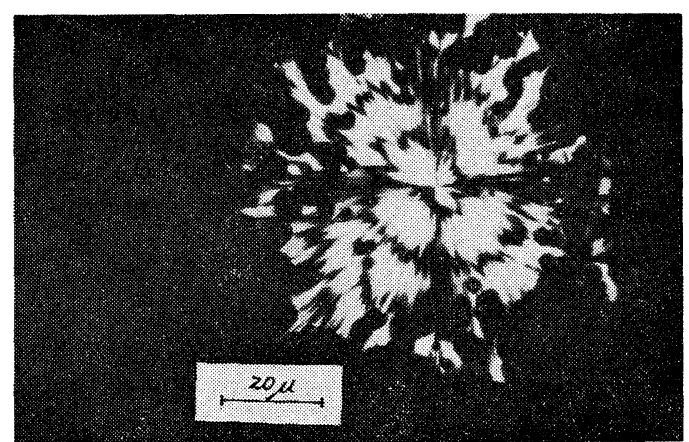

Figure 3. Banded spherulite and nodular structures formed at $90^{\circ} \mathrm{C}$ by $17-\mathrm{hr} \alpha$-pinene vapor exposure.

observed. A morphological transition of the spherulites is, therefore, considered to occur at $40^{\circ} \mathrm{C}$.

In Figure 2, the banded spherulites formed at $50^{\circ} \mathrm{C}$ are shown. These spherulites and those formed at $60^{\circ} \mathrm{C}$ have non-ringed overgrowth. ${ }^{2}$ This overgrowth is observed in the spherulites at every stage of their growth. This fibrillar overgrowth is, therefore, not due to the change in the growth mechanism which might be caused by an increase in the absorbed solvent. The overgrowth is observed in the spherulites formed at crystallization temperatures between $40^{\circ} \mathrm{C}$ and $70^{\circ} \mathrm{C}$. The higher the crystallization temperature is, the smaller the overgrowth, and at $70^{\circ} \mathrm{C}$, the overgrowth is no longer observed.

Figure 3 shows the spherulite formed at $90^{\circ} \mathrm{C}$, and similar spherulites with this type are also observed at temperatures above $70^{\circ} \mathrm{C}$. The black spots around the spherulite are nodular structures grown from the film which will be described

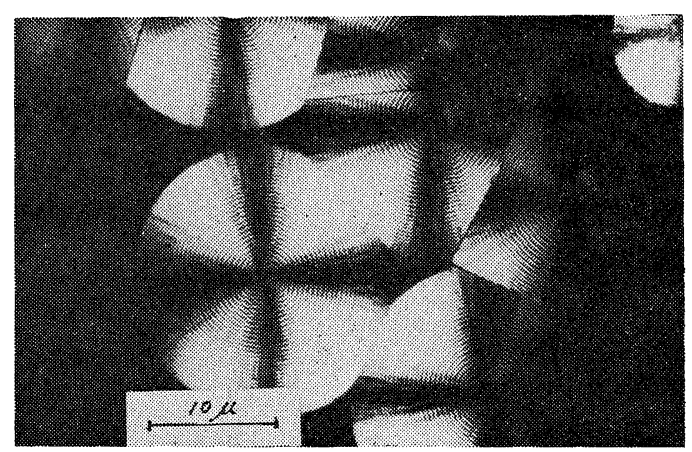

Figure 4. Closely spaced banded spherulites formed at $36^{\circ} \mathrm{C}$ by 5 -hr tetralin vapor exposure.

elsewhere in detail.

At the crystallization temperature rises above $80^{\circ} \mathrm{C}$, the number of spherulites formed rapidly decreases, and above $110^{\circ} \mathrm{C}$ no spherulite can be observed.

Figure 4 shows the spherulites formed at $36^{\circ} \mathrm{C}$ by tetralin vapor exposure. The temperature difference between the polymer film and tetralin was kept at $10^{\circ} \mathrm{C}$. In this case the spherulites have more closely spaced concentric rings than those formed by $\alpha$-pinene vapor exposure, and are negatively birefringent.

Above $50^{\circ} \mathrm{C}$, the spherulites cannot be formed by tetralin vapor exposure.

\section{REFERENCES}

1. J. M. Barrales-Rienda and J. M. G. Fatou, Kolloid-Z. Z. Polym., 244, 317 (1971).

2. J. H. Magill, J. Polym. Sci., Part A-2, 9, 815 (1971). 